\title{
Increasing Compliance and Task Completion in a Child with Borderline Intellectual Functioning: An Application of the Behavior Modification Principle
}

\author{
Mutia Aprilia Permata Kusumah ${ }^{\mathrm{a}}$ and Sri Redatin Retno Pudjiati ${ }^{\mathrm{b} *}$ \\ ${ }^{a}$ Faculty of Psychology, Universitas Indonesia, Depok, Indonesia; ${ }^{b}$ Department of \\ Developmental Psychology, Faculty of Psychology, Universitas Indonesia, Depok, Indonesia \\ *Corresponding author: \\ Sri Redatin Retno Pudjiati \\ Developmental Psychology Department \\ Faculty of Psychology, Universitas Indonesia \\ J1. Lkr. Kampus Raya, Depok, Jawa Barat \\ Indonesia, 16424 \\ Tel.: +62 217270004 \\ Email address: retno-pj@ui.ac.id
}




\title{
Increasing Compliance and Task Completion in a Child with Borderline Intellectual Functioning: An Application of the Behavior Modification Principle
}

\begin{abstract}
Behavior modification has been proven to increase the probability of desirable behavior in various settings. Although a lot of research has shown this method of intervention to be effective, few studies have been conducted with participants who have borderline intellectual functioning (BIF). The current case study aims to evaluate whether the application of the behavior modification principle; specifically, positive reinforcement, would result in an increased percentage of compliance and task completion in a 7 yearold child with BIF. Types of reinforcement used were consumable and social. A multiple-baseline across the behavior design was used to evaluate the intervention. While the intervention for compliance was being introduced, the task completion was still at the baseline phase for nine more trials. All sessions were conducted in the participant's house. Data collected indicate that delivering consumable and social reinforcing feedback to the participant resulted in an increase of $40.6 \%$ compliance over baseline, exceeding the initial target. The participant also showed an increased percentage of task completion of $26.9 \%$ over baseline, using the same kinds of reinforcement. The intervention produced similar positive results on both behaviors, even though the task completion was intervened in later than the compliance. These results also suggest that the application of positive reinforcement is successful in increasing compliance and task completion ability in a child with BIF.
\end{abstract}

Keywords: behavior modification; borderline intellectual functioning; compliance; task-completion.

\section{Introduction}

Behavior modification is an approach that involves manipulating an individual's current environment to change their behavior in order to enhance their ability to function on a daily basis (Martin \& Pear, 2015). This approach could be applied to decrease the chance of behavioral excess from occurring, or otherwise to increase the behavioral deficit so better behavior could happen more often in the future. Interventions using behavior modification have been applied successfully in many areas, including developmental disabilities, mental illness, education and special education, rehabilitation, and community psychology (Miltenberger, 2012). Furthermore, one of the basic principles in behavior modification; namely, positive reinforcement, has been proven to effectively increase behavioral deficits in individuals with or without specific psychological disorders (e.g., Carter, 2010; Knox, Rue, Lamb, \& Luiselli, 2012; Koffarnus, et al., 2013). Despite the promising results, behavior modification is still mostly being used to treat children diagnosed with neurodevelopmental disorders, such as attention-deficit/hyperactivity disorder, autism spectrum disorder, and intellectual disability (e.g., Lakhan, 2014; Pfiffner \& Haack, 2014; Wong, et al., 2013). There are only few studies which explored the application of behavior modification, even without positive reinforcement, in a population of children without specific diagnoses; most applications are found only in conditions that urgently need psychological attention. One of these conditions is borderline intellectual functioning (BIF). 
BIF is a categorization of intelligence in which the individual has an IQ score in the 71-84 range, as measured by a standardized intelligence test. The term condition is used because BIF was no longer considered as mental disorder as of the third edition of the Diagnostic and Statistical Manual of Mental Disorders (DSM-III), which served as the diagnostic manual (Wieland \& Zitman, 2016). Previously, BIF was considered the mildest kind of intellectual disability. Nonetheless, children with BIF are still at greater risk of experiencing academic problems compared to children in the typical development range for their age (Fenning, Baker, Baker, \& Crnic, 2014). Children with BIF need more time and more repetition to be able to learn new things. In classroom settings, they experience more difficulty understanding class materials, executing instructions, answering questions, concentrating on tasks given, and so on. However, children with BIF lack some common observable characteristics of intellectual disorders such as. distinct facial features or very limited speech production. Because of the lack of outwardlytelling characteristics, children with BIF are often perceived as plain lazy or stupid by those without sufficient knowledge about the condition, including parents and teachers.

In addition to their academic problems, children with BIF are also at greater risk of poor psychosocial outcomes and maladaptive functioning than typical children (Fenning, et al., 2014). Moreover, boys with BIF have been found to show a higher prevalence of antisocial behavior, such as authority avoidance, property destruction, physical aggression, and stealing, than their typically developed counterparts (Douma, Dekker, de Ruiter, Tick, \& Koot, 2007). This finding aligns with that of Zajenkowski and Zajenkowska (2015), which stated that the ones with the most limited cognitive control are associated with the poorest self-regulation and most direct aggression.

The current case study involves one participant with BIF who showed persistent noncompliance to authority figures such as parents and teachers. He was reported as not finishing his academic tasks, especially the ones that involved copying a sum of text. In addition, he was always complaining and trying to bargain his way out of his assignments. Hence, an intervention using the behavior modification principle was designed to overcome the participant's noncompliant behavior. In other words, the goal was to increase his compliance with authority as well as his ability to complete tasks. Compliance is defined as initiating a response within 5-10 seconds after a command is given (Axelrod \& Zank, 2012; Starkweather-Lund, 2001). A criterion of a $\geq 60 \%$ compliance rate is adopted to distinguish between compliant and noncompliant children (Axelrod \& Zank, 2012). Meanwhile, task completion was defined by Ramsey, Jolivette, Patterson, and Kennedy (2010) as a specific number of items completed by the child, as evidenced by pen or pencil marks near the items.

The purpose of this study is to examine the effect of applying the behavior modification principle; specifically, positive reinforcement, on increasing compliance and task completion ability in a child with BIF. Types of positive reinforcement provided were consumable and social. Considering results obtained in previous studies (e.g., Carter, 2010; Knox, Rue, Lamb, \& Luiselli, 2012; Koffarnus, et al., 2013), the hypothesis was that the application of positive reinforcement would increase the percentage of compliance and task completion for this particular child. 


\section{Methods}

\section{Participant}

A 7 year-old boy diagnosed with BIF participated in this study. The participant was a first-grade student in a private Islamic school. He was referred to a community health center in Depok for psychological treatment. He was initially assessed for his difficulties in learning (especially in reading and writing), emotional outbursts, and physical aggression. A diagnosis of BIF was given after considering results from various standardized assessment measures, such as the Wechsler Intelligence Scale for Children-Revised (WISC-R), Raven's Coloured Progressive Matrices $^{\mathrm{TM}}$, and The Marianne Frostig Developmental Test of Visual Perception; these were completed alongside informal parent and teacher interviews as well as direct observations of the child in various settings. In December 2016, the participant had an IQ of 80 as measured with the WISC-R.

\section{Research Design}

The current study uses a single-case research design. A multiple-baseline across behaviors design was used to examine the effects of intervention. Behaviors included in the current intervention were compliance and task completion; thus, the utilization of two baselines. Baseline data for the compliance behavior were obtained first. Once the baseline data were stable, intervention for the compliant behavior was introduced, while the baseline for task completion continued. During this period, the compliance rate was expected to increase, while the task completion rate was expected to continue at baseline levels. The intervention for the task completion would be started later, after its baseline phase showed stability. The intervention as a whole would be considered effective if higher rates for each behavior were observed in the participant at each point at which the intervention was initiated.

\section{Measures}

In this study, compliance was defined as the initiation of movement toward getting the command done within 5 seconds after each instruction was initially given. The intervention would be considered successful if the participant could show a minimum of an average compliance rate of $60 \%$. Thus, the participant would also show a higher compliance mean compared to the baseline phase. The percentage of compliance was calculated by dividing the number of instances of compliance by the number of commands given in each trial and multiplying by $100 \%$. Data were then recorded in the recording sheet in Table 1.

Table 1

Recording Sheet of Compliance Behavior

\begin{tabular}{|c|c|c|c|c|}
\hline \multirow{2}{*}{ Session } & \multirow{2}{*}{ Target } & \multicolumn{2}{|c|}{ Percentage of Compliance (\%) } & \multirow[b]{2}{*}{ Notes } \\
\hline & & Trial $1 \quad$ Trial 2 & Trial 3 & \\
\hline 1 & (no target-baseline phase) & & & \\
\hline 2 & (no target-baseline phase) & & & \\
\hline 3 & (no target-baseline phase) & & & \\
\hline 4 & $\begin{array}{l}\text { Initiating movement }<\mathbf{2 0} \mathbf{s} \text { after the instruction } \\
\text { given, at least for } 2 / 5 \text { instructions in } 2 \text { trials }\end{array}$ & & & \\
\hline 5 & $\begin{array}{l}\text { Initiating movement }<\mathbf{2 0} \mathrm{s} \text { after the instruction } \\
\text { given, at least for } 3 / 5 \text { instructions in } 2 \text { trials }\end{array}$ & & & \\
\hline 6 & $\begin{array}{l}\text { Initiating movement }<\mathbf{1 5} \mathrm{s} \text { after the instruction } \\
\text { given, at least for } 2 / 5 \text { instructions in } 1 \text { trial }\end{array}$ & & & \\
\hline 7 & $\begin{array}{l}\text { Initiating movement }<\mathbf{2 0} \mathbf{s} \text { after the instruction } \\
\text { given, at least for } 2 / 5 \text { instructions in } 2 \text { trials }\end{array}$ & & & \\
\hline 8 & $\begin{array}{l}\text { Initiating movement }<\mathbf{1 0} \mathrm{s} \text { after the instruction } \\
\text { given, at least for } 3 / 5 \text { instructions in } 2 \text { trials }\end{array}$ & & & \\
\hline
\end{tabular}


Table 1, cont.

Recording Sheet of Compliance Behavior

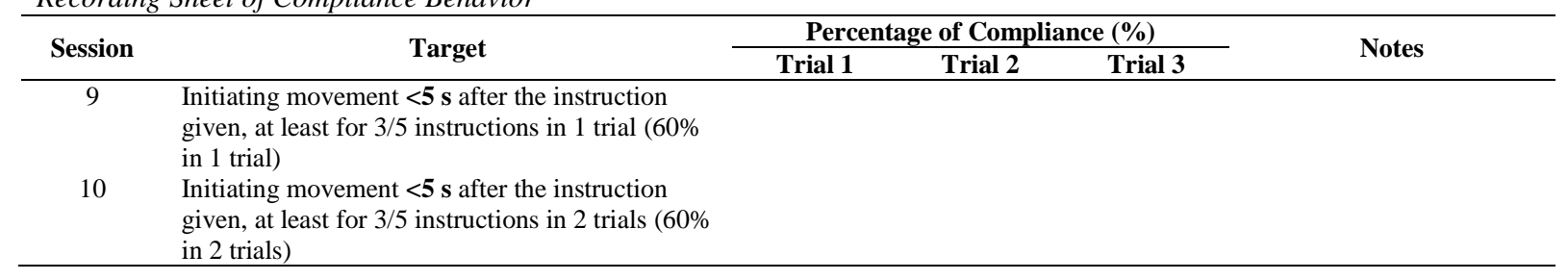

Three trials were conducted during every session. In each trial, five commands were given to the participant. The commands acted as discriminative stimulus $\left(\mathrm{S}^{\mathrm{D}}\right)$ to trigger the compliant behavior in the participant. To make sure that each command was delivered with the same effectiveness, the command was given one at a time, by a person in close proximity to the participant, with specific and direct sentences and while making eye contact (Starkweather-Lund, 2001). The commands were designed to be similar to common requests made by the participant's parents at home, since the noncompliant behavior was often directed at them. Table 2 summarizes the templates of commands used in this study. Commands were given in a random fashion and spoken as naturally as possible, depending on the situation at hand. For example, if the participant accidentally spilled some of his drink, the instructor would command him to wipe up the spill.

Table 2

List of Commands

\begin{tabular}{ll}
\hline Purpose of the Command & Command $\left(\mathbf{S}^{\mathbf{D}}\right)$ \\
\hline To get a certain object in the house & "Tolong ambilkan [nama benda]" \\
& ("Get me [object], please") \\
To put a certain object in the house & "Tolong taruh [nama benda] di [nama tempat]" \\
& ("Put [object] on/in [location], please") \\
To start a certain activity & "Ayo sini/sana [nama aktivitas]" \\
& ("Come, start [activity]") \\
To stop doing a certain activity & "Selesai ya [nama aktivitas]-nya" \\
& ("Stop [activity], please") \\
\hline
\end{tabular}

Considering the participant's limited ability in reading and writing, the tasks were designed to help him practice both. One task was to write a copy of syllables on a worksheet, completing as many as possible during a period of 5 minutes. One worksheet page consisted of 3 rows of syllables. In each row, 5 syllables were written with 5 different vocals. The syllables in each row were arranged in the exact order of the vocals within; so if the first row is 'a,' 'i,' ' $u$,' 'e,' 'o,' the second one must be 'ba,' 'bi,' 'bu,' 'be,' 'bo,' and so forth. To copy each syllable, the participant must listen to what was being dictated by instructor, because the instructor randomly picked syllables from the worksheet. The participant then had to read the syllables in each row to find the one that was dictated and write down a copy of it. In this exercise, the dictated syllables provided discriminative stimuli for task-completing behavior. Similar to compliant behavior, the intervention would be affirmed as successful if the result showed a higher task completion mean than in the baseline phase. In addition to that, the participant was also expected to complete all the worksheets given within 5 minutes (100\% of task compliance), in at least 2 trials. The percentage of task completion was calculated by dividing the number of syllables copied in each trial by the targeted number of syllables (average number in the baseline phase $+60 \%$ ). All data were then recorded in the recording sheet in Table 3. 
Table 3

Recording Sheet of Task-completion

\begin{tabular}{|c|c|c|c|c|}
\hline \multirow{2}{*}{ Session } & \multirow{2}{*}{ Target } & \multicolumn{2}{|c|}{ Percentage of Task-completion (\%) } & \multirow[b]{2}{*}{ Notes } \\
\hline & & $\begin{array}{lr}\text { Trial 1 } & \text { Trial } 2 \\
\end{array}$ & Trial 3 & \\
\hline 1 & (no target-baseline phase) & & & \\
\hline 2 & (no target-baseline phase) & & & \\
\hline 3 & (no target-baseline phase) & & & \\
\hline 4 & (no target-baseline phase) & & & \\
\hline 5 & (no target-baseline phase) & & & \\
\hline 6 & (no target-baseline phase) & & & \\
\hline 7 & $\begin{array}{l}\text { Copying } \mathbf{2 0 \%} \text { more syllables than the } \\
\text { average number obtained in baseline, at least } \\
\text { in } 2 \text { trials ( }+20 \% \text { in } 2 \text { trials) }\end{array}$ & & & \\
\hline 8 & $\begin{array}{l}\text { Copying } \mathbf{3 0 \%} \text { more syllables than the } \\
\text { average number obtained in baseline, at least } \\
\text { in } 2 \text { trials }(+30 \% \text { in } 2 \text { trials) }\end{array}$ & & & \\
\hline 9 & $\begin{array}{l}\text { Copying } \mathbf{5 0 \%} \text { more syllables than the } \\
\text { average number obtained in baseline, at least } \\
\text { in } 2 \text { trials ( }+50 \% \text { in } 2 \text { trials) }\end{array}$ & & & \\
\hline 10 & $\begin{array}{l}\text { Copying } 60 \% \text { more syllables than the } \\
\text { average number obtained in baseline, at least } \\
\text { in } 2 \text { trials ( }+60 \% \text { in } 2 \text { trials) }\end{array}$ & & & \\
\hline
\end{tabular}

\section{Procedure}

An application of ethical clearance was submitted to the Research Committee of Universitas Indonesia prior to the start of study. Written informed consent was provided to the participant's parents. The parents agreed to involve their child in this study and were fully aware of their option to withdraw at any point during the intervention. The participant himself understood that he would be assigned to do some tasks, some of which involved writing, and that there were possibilities of a reward for completing tasks.

Prior to the initiation of the intervention, a functional behavioral assessment was conducted to identify the antecedents, behaviors, and consequences of the target behaviors.

Table 4

Functional Behavioral Assessment of the Target Behaviors

\begin{tabular}{lll}
\hline Antecedents & Behavior & Consequences \\
\hline $\begin{array}{l}\text { Verbal command was given by the } \\
\text { parents }\end{array}$ & $\begin{array}{l}\text { Deficit of compliant behavior } \\
\text { (Function: Avoidance) }\end{array}$ & Participant did not have to comply with the command \\
Participant worked on academic task & $\begin{array}{l}\text { Deficit of task-completing behavior } \\
\text { (Function: Avoidance) }\end{array}$ & $\begin{array}{l}\text { Participant could get away with working on just a little } \\
\text { bit of task. }\end{array}$ \\
\hline
\end{tabular}

Following the functional behavioral assessment, another assessment was held to determine the order of favorable reinforcements for the participant. Data were collected by interviewing the participant and his mother. Results showed that the favorable reinforcements were for consumables. In order from most favorable to least, they were chocolate, sausages, sweet drinks (e.g., chocolate milk, orange juice), and fish crackers. Meanwhile, the favorable social reinforcement was praise, specifically for a job well done and in recognition of how compliant the participant was.

After the assessments, baseline data for compliance and task completion were obtained. There were nine trials for the former behavior and 18 trials for the latter. During the baseline phase for compliance, the instructor issued five commands to the participant in each trial. Compliant 
behavior was recognized by thanking the participant, but without giving any reinforcement. Meanwhile, in the baseline phase for task completion, the participant was given instructions to copy the writing of as many syllables as he could in five minutes for each trial, and no reinforcement was given.

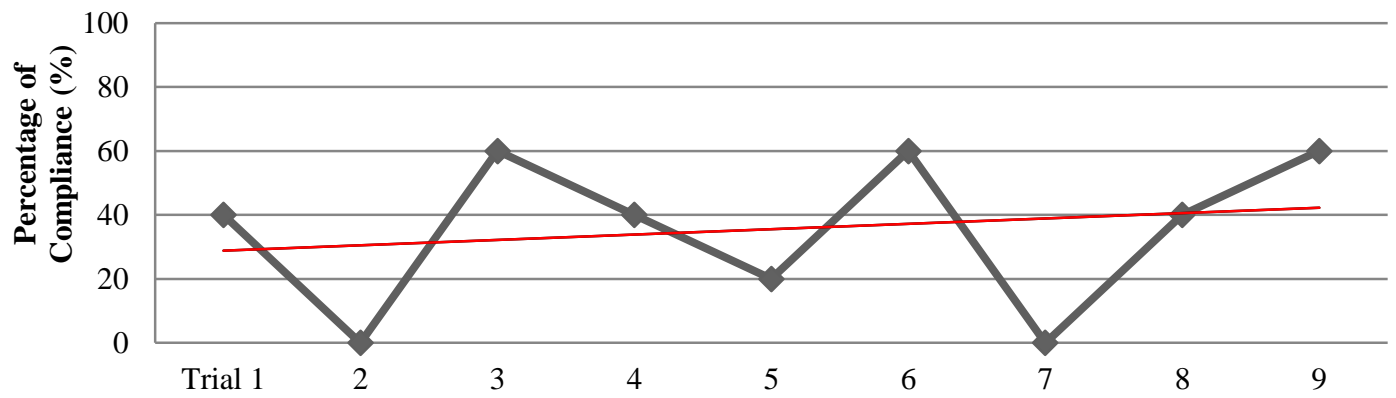

Figure 1. Baseline phase of compliance.

Figure 1 illustrates the percentage of compliance shown by the participant. The baseline depicts a variable pattern. It does not show stability, even after the ninth data point. However, the pattern is predictable. The mean percentage of the participant's compliance was $35.6 \%$.

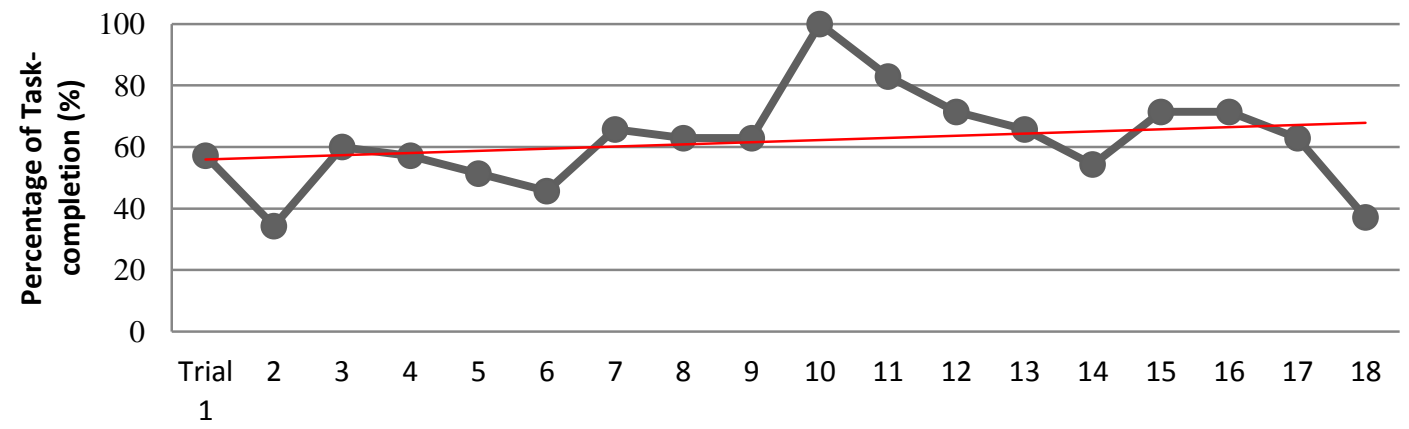

Figure 2. Baseline phase of task-completion.

The baseline data of task completion showed the average number of syllables which the participant was able to write within five minutes was 22 . This number was later multiplies by $60 \%$ and itself to determine the target number of syllables. The result was 35 . Hence, the task would be considered fully or $100 \%$ complete if the participant could write 35 syllables down in five minutes. 
As shown in Figure 2, the mean percentage of the participant's task completion was $61.9 \%$. In trial 10, the participant showed a one-time success in completing $100 \%$ of the task. During the aforementioned trial, intervention for the compliant behavior was introduced. Thus, the delivery of reinforcement was begun after the participant began showing the targeted behavior. In trial 11 and later trials, the task completion percentage began to decrease to a lower rate because the behavior for completing the task was again not reinforced.

The intervention for this study was conducted by the first author as a master's degree student majoring in child clinical psychology in the Faculty of Psychology at the Universitas Indonesia. The aforementioned author handled the case under the supervision of the second author as part of her pursuit of her child psychologist title. The second author herself is a certified child psychologist registered in Himpunan Psikologi, Indonesia.

The intervention was conducted over 10 sessions. The participant and his parents agreed to hold the sessions at their house five times a week. Each session was conducted for about one hour in the afternoon. The sessions always started with a compliance trial. The instructor gave five verbal commands to the participant, interspersed over approximately 15 minutes. The instructor then thanked the participant and delivered positive reinforcements to him in each instance that the participant completed the targeted response. After recording the participant's response time on the recording sheet, the task completion trial would start. Prior to the first task completion trial, the instructor explained what was expected of the participant in the trials. Then, a timer was set to ring after five minutes. When the timer rang, the instructor counted the number of syllables copied by the participant and recorded it. Positive reinforcement was given when the target for that particular trial was achieved. Before initiating the next task completion trial, the participant was allowed a 15-minute "break," during which the instructor would give him five different commands as another compliance trial. The activities were repeated until there were three compliance trials and three task completion trials in each session.

In each session, positive reinforcement of praise was given every time the participant achieved the targeted percentage of compliance: "Hebat! [Nama partisipan] langsung menurut setelah diminta ya!" ("Good job! [Name of participant] did what I requested immediately!" Meanwhile, when the participant achieved the targeted percentage of task completion, the participant would get this praise: "Wah, [name of participant] berhasil banyak menulis ya! Senang sekali [nama pemberi instruksi] melihatnya" ("Wow, [name of participant) sure could write a lot! [name of instructor] is so happy to see you like this). Immediately after the praise was delivered, consumable reinforcements were also given. For the initial sessions, the participant's most favorite consumable reinforcements of chocolate and sausage were used (both held the same value). Gradually, the reinforcements were switched over to the less favorite ones (orange juice, followed by fish crackers for some of the final sessions). The consumable reinforcements were given only in a small amounts (e.g., 4 chips of chocolate, 1/5 cup of chocolate milk) to avoid oversatiation, as that could decrease the effectiveness of the consumables used as reinforcements.

\section{Data Analysis}

In order to be analyzed, the data were displayed visually in graphs. Visual analysis was then used to examine the effects of intervention on increasing compliant and task completion behavior, which was conducted at two different starting points. Data level and trend of the patterns within the baseline and intervention phases were inspected. Level is the mean score of all data obtained 
in each phase and trend is the best-fitting straight line for the aforementioned data (Kratochwill, et al., 2010). In the current study, the mean percentage for the baseline and intervention phase was obtained by summing up all percentages obtained in respective phases and dividing by the number of trials. The researcher also inspected data patterns between phases using the immediacy of the effect and overlap. The immediacy of effect is defined as a level change between the last three data points in one phase and the first three data points in the next, while overlap is the proportion of data in one phase that overlaps with data in another phase (Kratochwill, et al. 2010).

\section{Results}

The participant completed all 10 sessions which were designed for him. There were 30 trials in total. The intervention for compliance was introduced after the ninth trial of baseline. Meanwhile, for task-completing behavior, baseline data continued to be obtained until the eighteenth trial, after which the intervention was introduced.

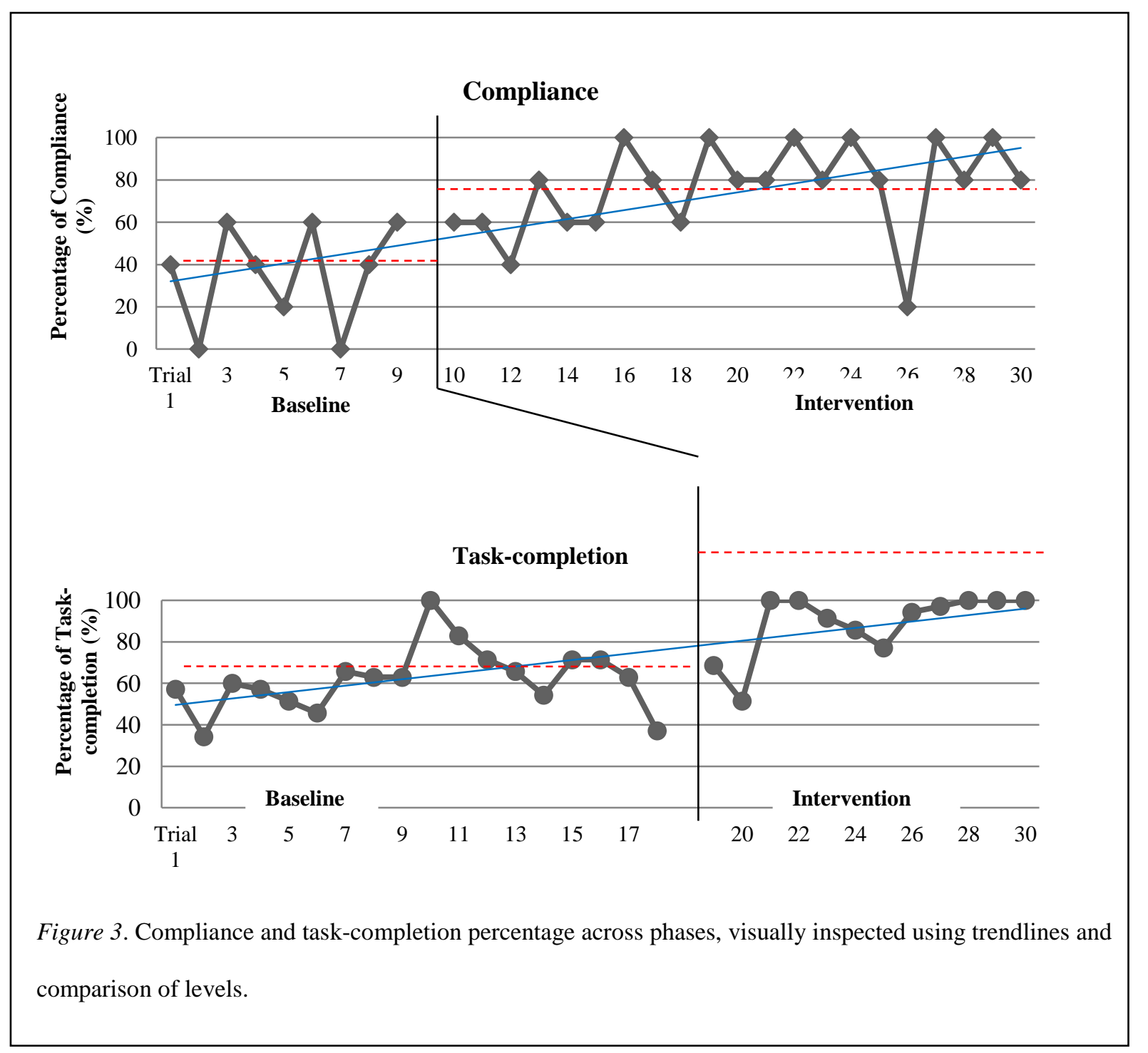


Figure 3 depicts a higher level and ascending trend of compliance in the intervention phase. The mean percentage of compliance in the baseline phase was 35.6\%. Within the intervention phase, there was one data point which descended rapidly. That data point refers to trial 26 , the trial in which the participant, who had only recently woken up from his nap, was upset and frequently whined over little things. Regardless of that particular data point, the mean percentage of compliance still increased to $76.2 \%$ after the intervention was introduced, surpassing the targeted percentage of $60 \%$. The obtained percentage was also an increase of $40.6 \%$ over baseline. Similar positive results were seen in the task-completing behavior. The rates for this behavior also increased after the intervention was introduced. The mean percentage of $61.9 \%$ became $88.8 \%$ in the intervention phase. This means that there was an increase of $26.9 \%$ over baseline. There were also five points at which the participant finished $100 \%$ of the whole task given, with three of those occurring during the last three trials conducted during intervention. Therefore, the target for task completion was achieved. As a visual, one can see that the level of task completion in the intervention phase is higher than the one in the baseline phase. The ascending trend is also quite visible. Based on the increasing trend and the achievement of higher level or mean of each targeted behavior, it can be concluded that the intervention, no matter at which point it was introduced, could increase the participant's compliance and task completion rate.

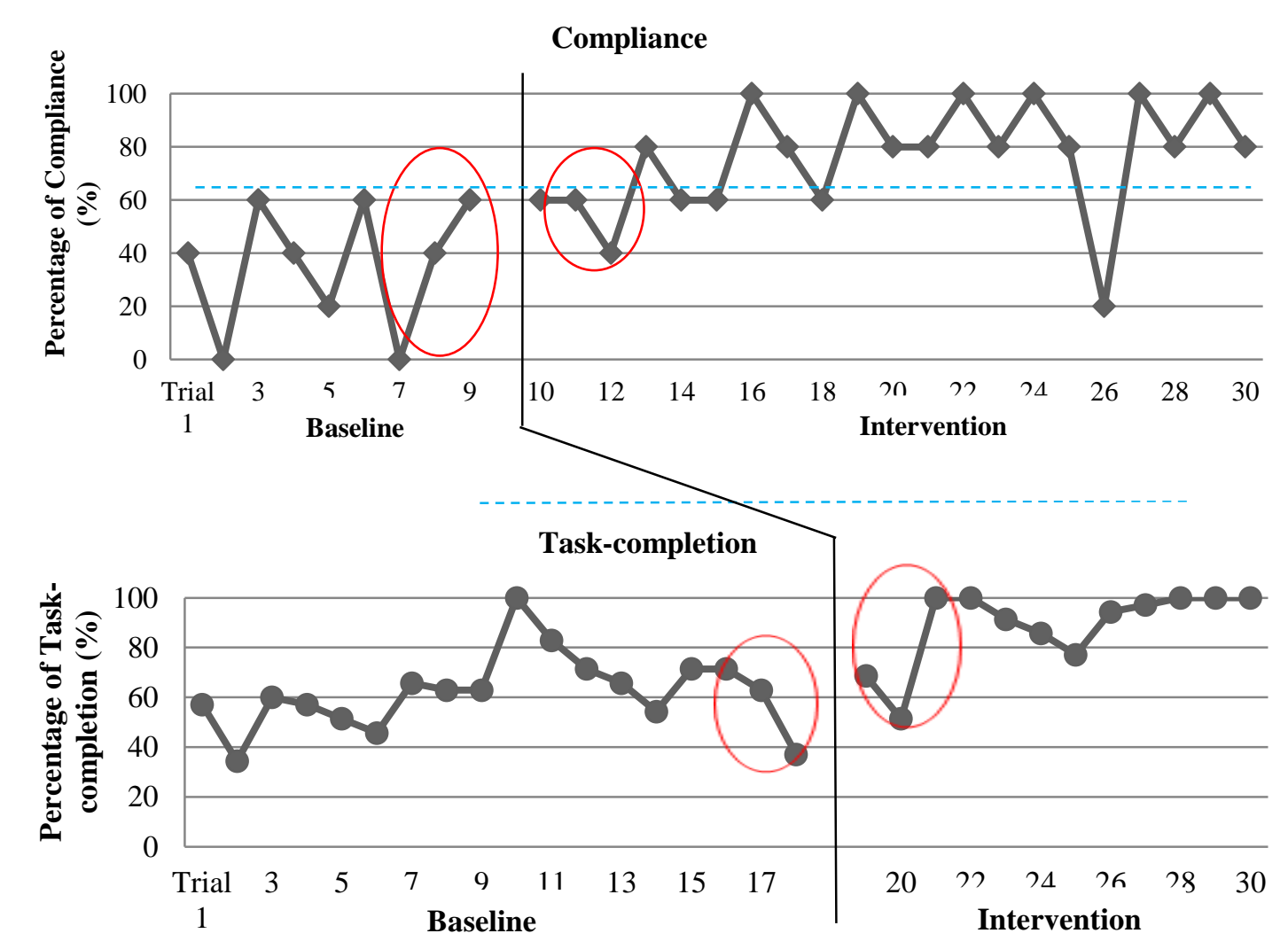

Figure 4. Compliance and task-completion percentage across phases, visually inspected using the immediacy of the effect and overlap. 
As seen in Figure 4, circled data points in the task compliance graph depict a rather immediate effect demonstrated by the intervention. There is also one data point in baseline phase which overlaps with the ones in the intervention phase. The percentage of compliance for that particular data point is $100 \%$. During the baseline phase, the only task completed at $100 \%$ was achieved in trial 10, the one trial which was conducted right after the delivery of reinforcement for succeeding in the compliance trial. Data points for the eleventh and later sessions descends, reaching a mean percentage of $68.6 \%$. However, the obtained mean is still higher compared to the mean percentage of trials 1-9 (59.7\%), in which the intervention for the other behavior had not yet been introduced. Thus, we might assume that the increased task completion rate was definitely affected by the intervention, even when the intervention was not aimed at the taskcompleting behavior. Despite other promising evidence which were depicted in the Figure 3, the circles in the compliance graph show that the effect of the intervention did not happen immediately enough, as seen in Figure 4. There are also three data points in the baseline phase which overlapped with data points in the intervention phase. The overlapping data weakens the assumption that the intervention had a great effect on the participant's increased compliance.

\section{Discussion}

As hypothesized, the findings of the current study yielded similar results to studies which also obtained positive effects in utilizing positive reinforcement to increase target behaviors (e.g., Carter, 2010; Knox, Rue, Lamb, \& Luiselli, 2012; Koffarnus, et al., 2013). The results obtained in this study indicate that the application of positive reinforcement provides increasing rates of compliance and task completion in a child with BIF. Reinforcing his efforts with consumables and social reinforcements in any instant in which he completed the targeted percentage caused the participant to show an increased average rate of task completion, up to as much as $26.9 \%$ over baseline. The target rate for the task completion was also achieved. The participant was able to finish $100 \%$ of the whole task in five of the trials, surpassing the target of only 2 trials. This result indicates that the application of positive reinforcement increased the participant's taskcompleting behavior, with only a little time needed for the intervention to demonstrate its effect. In addition, there is high possibility that the participant's task-completing behavior was vicariously affected by the intervention aimed at compliance. The data from the baseline phase of task completion obtained a higher average percentage after the intervention for the compliance was introduced. This finding contradicts Kazdin (2013) who implied that during an intervention for one behavior, the other behavior which is still in baseline should remain stable in data points.

On the other hand, results obtained for the compliant behavior were quite different. It is true that the participant's mean percentage of compliance gained an increase of $40.6 \%$ over the baseline phase. The mean percentage recently obtained (76.2\%) also surpassed the initial target of $60 \%$. These results indicate that there was an improvement in the participant's behavior which was caused by the intervention. However, visual analysis shows that the intervention produced a little less immediate and weaker effect on the compliant behavior compared to its effect on the other behavior.

In addition to the promising results, this study contributes to extending the literature of behavior modification on increasing target behavior in children with BIF. Until now, there have been only 
few published studies which involved children with BIF. This study could also be useful for future research targeting increased compliance and/or task-completing behavior.

There are several limitations in the current study that should be addressed. First, the intervention conducted was short in length. There was not enough time to extend the baseline phase to make it more stable, or to prolong the intervention phase for the purpose of maintenance. The second limitation of this study was the research design: only two behaviors were measured. To strengthen the multiple-baseline across behavior design, adding at least one other behavior would be very helpful in analyzing the effectiveness of the intervention. Future research should involve at least three behaviors that need to be changed. The last limitation is concerning stimulus generalization. Stimulus generalization occurs when a response is being performed in different circumstances (e.g., at a different time, with different people) from when it was first learned (Miltenberger, 2012). Considering that previous functional behavioral assessments found that the participant's noncompliance was most often seen with his parents, the intervention was meant to involve the participant's mother as a second instructor. She was planning to instruct the second and third trial of each session in order to provide stimulus generalization within the intervention. However, the mother's work schedule turned out not to match with the allocated intervention times. Therefore, the stimulus generalization component was not practiced as planned and the researcher acted as the sole instructor during the entire intervention period. Sessions involving the mother as the instructor should be conducted later for the purpose of stimulus generalization. In addition to that, it would be better for future research if the intervention program, especially the one for increased compliance, was designed to involve at least two instructors, one or more of whom routinely interact with the child in his daily settings (e.g., parents, caregiver, teacher).

\section{References}

Axelrod, M. I. \& Zank, A. J. (2012). Increasing classroom compliance: Using a high-probability command sequence with noncompliant students. Journal of Behavioral Education, 21, 119. doi:10.1007/s10864-011-9145-6

Carter, S. L. (2010). A comparison of various forms of reinforcement with and without extinction as treatment for escapemaintained problem behavior. Journal of Applied Behavior Analysis, 43(3), 543-6.

Douma, J. C., Dekker, M. C., de Ruiter, K. P., Tick, N. T., \& Koot, H. M. (2007). Antisocial and delinquent behaviors in youths with mild or borderline disabilities. American Journal on Mental Retardation, 112(3), 207-220.

Fenning, R. M., Baker, J. K., Baker, B. L., \& Crnic, K. A. (2014). Parent-child interaction over time in families of young children with borderline intellectual functioning. Journal of Family Psychology, 28(3), 326-335. doi: http://dx.doi.org/10.1037/a0036537

Kazdin, A. E. (2013). Behavior modification in applied settings (7th ed.). Long Grove, IL: Waveland Press.

Knox, M., Rue, H. C., Wildenger, L., Lamb, K., \& Luiselli, J. K. (2012). Intervention for food selectivity in a specialized school setting: Teacher implemented prompting, reinforcement, and demand fading for an adolescent student with autism. Education \& Treatment of Children, 35(3), 407-417.

Koffarnus, M. N., Wong, C. J., Fingerhood, M., Svikis, D. S., Bigelow, G. E., \& Silverman, K. (2013). Monetary Incentives to Reinforce Engagement and Achievement In a Job-skills Training Program for Homeless, Unemployed Adults. Journal of Applied Behavior Analysis, 46(3), 582-91.

Kratochwill, T. R., Hitchcock, J., Horner, R. H., Levin, J. R., Odom, S. L., Rindskopf, D. M \& Shadish, W. R. (2010). Singlecase designs technical documentation. Retrieved from http://ies.ed.gov/ncee/wwc/pdf/wwc scd.pdf

Lakhan, R. (2014). Behavioral management in children with intellectual disabilities in a resource-poor setting in Barwani, India. Indian journal of psychiatry, 56(1), 39.

Martin, G., \& Pear, J. J. (2015). Behavior modification: What it is and how to do it (10th Ed.). Upper Saddle River, N.J: Pearson Education, Inc.

Miltenberger, R. G. (2012). Behavior modification: Principles and procedures (5th Ed.). Belmont, CA: Wadsworth, Cengage Learning.

Wieland, J., \& Zitman, F. G. (2016). It is time to bring borderline intellectual functioning back into the main fold of classification systems. BJPsych Bulletin, 40(4), 204-206. http://doi.org/10.1192/pb.bp.115.051490 
Pfiffner, L. J. \& Haack, L. M. (2014). Behavior Management for School Aged Children with ADHD. Child and Adolescent Psychiatric Clinics of North America, 23(4), 731-746. http://doi.org/10.1016/j.chc.2014.05.014

Ramsey, M. L., Jolivette, K., Patterson, D. P., \& Kennedy, C. (2010). Using choice to increase time on-task, task-completion, and accuracy for students with Emotional/Behavior disorders in a residential facility. Education \& Treatment of Children, 33(1), 1-21.

Starkweather-Lund, A. (2001). Training teachers to give effective commands: Effects on student compliance, academic engagement, and academic responding. $\quad$ Retrieved from https://search.proquest.com/docview/275867323? accountid=17242

Wong, C., Odom, S. L., Hume, K. Cox, A. W., Fettig, A., Kucharczyk, S., ... Schultz, T. R. (2013). Evidence-based practices for children, youth, and young adults with Autism Spectrum Disorder. Chapel Hill: The University of North Carolina, Frank Porter Graham Child Development Institute, Autism Evidence-Based Practice Review Group.

Zajenkowski, M., \& Zajenkowska, A. (2015). Intelligence and aggression: The role of cognitive control and test related stress. Personality and Individual Differences, 81, 23-28. 